\title{
Production of transglutaminase in glutathione-producing recombinant Saccharomyces cerevisiae
}

Yoko Hirono-Hara ${ }^{1 \dagger}$, Miyuu Yui ${ }^{1+}$ and Kiyotaka Y. Hara ${ }^{1,2^{*}}$ (1)

\begin{abstract}
Transglutaminase (TG) catalyzes the formation of cross-links between proteins. TG from Streptoverticillium mobaraense (SmTG) is used widely in food, cosmetic, biomaterial and medical industries. SmTG is occasionally supplied as a mixture with the activator peptide glutathione. Currently, glutathione is industrially produced using a budding yeast, Saccharomyces cerevisiae, because of its intracellular high content of glutathione. In this study, active SmTG was produced together with glutathione in S. cerevisiae. SmTG extracted from S. cerevisiae expressing SmTG showed cross-linking activity when BSA and sodium caseinate were substrates. The cross-linking activity of SmTG increased proportionally as the concentration of added glutathione increased. Furthermore, SmTG was prepared by extracting SmTG from an engineered S. cerevisiae whose glutathione synthetic pathway was enhanced. The SmTG solution showed higher activity when compared with a SmTG solution prepared from a S. cerevisiae strain without enhanced glutathione production. This result indicates that a high content of intracellular glutathione further enhances active SmTG production in S. cerevisiae. S. cerevisiae co-producing SmTG and a higher content of glutathione has the potential to supply a ready-to-use industrial active TG solution.
\end{abstract}

Keywords: Transglutaminase, Glutathione, Streptoverticillium mobaraense, Yeast, Saccharomyces cerevisiae, Coproduction

\section{Key points}

- Streptoverticillium mobaraense transglutaminase ( $S m$ TG) is used widely in the food industry.

- $\operatorname{SmTG}$ is activated by the peptide glutathione.

- Active SmTG was produced in an engineered high glutathione-producing S. cerevisiae.
*Correspondence: k-hara@u-shizuoka-ken.ac.jp

${ }^{\dagger}$ Yoko Hirono-Hara and Miyuu Yui contributed equally to this work

${ }^{2}$ Graduate Division of Nutritional and Environmental Sciences, University

of Shizuoka, 52-1 Yada, Suruga-ku, Shizuoka 422-8526, Japan

Full list of author information is available at the end of the article

\section{Introduction}

Transglutaminase (TG; EC 2.3.2.13) is an acyl transferase that forms both intra- and inter-molecular isopeptide bonds in and between proteins. TG catalyzes an acyl transfer reaction between the $\gamma$-carboxyamide group of glutamine residues and the $\gamma$-amino group of lysine residues to form $\varepsilon$-( $\gamma$-glutamyl)lysine isopeptide bonds. Such reactions facilitate the polymerization of proteins (Folk 1980; Lorand and Conrad 1984; Kashiwagi et al. 2002).

TG is used widely in the food, chemical, medical and cosmetic industries because of its broad crosslinking activity (Ikura et al. 1981; Kurth and Rogers 1984; Savoca et al. 2018). In particular, TG is often used widely in the food industry to avoid chemical modification processes to link proteins (Kuraishi et al. 1997; Gerrard et al. 1998; Abou-Soliman et al. 2017), which often give rise to unwanted side reactions and 
require high-pressure/temperature conditions and chemical solvents (Miwa 2020). TG is distributed widely in nature and has been identified in bacteria and mammals. However, when focusing on the industrial use of TG, microbial transglutaminase produced by $S$. mobaraense ( $S m \mathrm{TG}$ ) is a major choice because of various advantages that include $\mathrm{Ca}^{2+}$ independence, higher reaction rates, thermostability, wider substrate specificity for acyl donors and a smaller molecular size when compared with other TGs (Ando et al. 1989; Nonaka et al. 1989; Kanaji et al. 1993; Miwa 2020).

The addition of glutathione has been reported to activate SmTG (Bönisch et al. 2007; Miwa 2020). Glutathione is an anti-oxidant tripeptide that is distributed widely among animals, plants and microorganisms, playing an important role in the protection of cells against oxidation and the maintenance of enzymes and other cellular components in the reduced state (Schmacht et al. 2017). Currently, industrial production of glutathione uses the budding yeast, Saccharomyces cerevisiae, because of its high intracellular glutathione content ( $\mathrm{Li}$ et al. 2004). SmTG mixed with yeast extract containing glutathione is commercially available (Bönisch et al. 2007; Miwa 2020). The mechanism of glutathione activating SmTG remains unresolved, although Bönisch et al. (2007) demonstrated that reduction of an unknown inhibitor(s) present in milk by glutathione improved crosslinking of casein (Bönisch et al. 2007). Therefore, production of both SmTG and glutathione using $S$. cerevisiae expressing $S m$ TG should be a promising, simple one-pot process to obtain highly active SmTG. In $S$. cerevisiae, glutathione biosynthesis is continuously catalyzed by glutathione synthase I (Gsh1) and glutathione synthase II (Gsh2) from three precursor amino acids (Li et al. 2004; Schmacht et al. 2017). We previously developed an engineered $S$. cerevisiae strain (GCI strain) whose glutathione biosynthesis was improved by overexpression of Gsh1 and Gsh2 (Hara et al. 2012).

Several studies have reported heterologous expression of SmTG in microorganisms such as Escherichia coli (Salis et al. 2015), Corynebacterium glutamicum (Itaya and Kikuchi 2008) and Pichia pastoris (Özçelik et al. 2019), whereas the glutathione-producing strain $S$. cerevisiae has never been used as a host strain. In the current study, S. cerevisiae was evaluated as a host strain to produce SmTG. Moreover, the produced $S m$ TG solution was active when expressed in the engineered S. cerevisiae GCI strain. The results demonstrate the potential of $S$. cerevisiae as a host strain to produce industrial levels of active $S m$ TG.

\section{Materials and methods}

\section{Strain and media}

Escherichia coli $\mathrm{DH} 5 \alpha$ cells were used for recombinant DNA manipulation. S. cerevisiae BY4741 strain [MAT $\alpha$ his $3 \Delta 1$ ura $3 \Delta 0$ leu $2 \Delta 0$ met $15 \Delta 0$ ] and the previously engineered glutathione-hyper producing yeast (GCI strain) (Hara et al. 2015) that overexpresses the GSH1 and GSH2 genes were used.

Escherichia coli transformants were grown in LuriaBertani medium (10 g/L tryptone, $5 \mathrm{~g} / \mathrm{L}$ yeast extract, $5 \mathrm{~g} / \mathrm{L} \mathrm{NaCl}$ ) supplemented with $100 \mu \mathrm{g} / \mathrm{mL}$ ampicillin. Yeast transformants were grown in rich yeast-extract peptone dextrose (YPD) medium $(10 \mathrm{~g} / \mathrm{L}$ yeast extract, $20 \mathrm{~g} / \mathrm{L}$ bacto-peptone, $20 \mathrm{~g} / \mathrm{L}$ glucose) supplemented with or without $0.5 \mu \mathrm{g} / \mathrm{mL}$ aureobasidin A (Takara Bio, Shiga, Japan), and in selective synthetic dextrose (SD) medium $(6.7 \mathrm{~g} / \mathrm{L}$ yeast nitrogen base without amino acids, $20 \mathrm{~g} / \mathrm{L}$ glucose) supplemented with appropriate concentrations of amino acids and nucleobases.

\section{Plasmid and yeast transformation}

The gene encoding TG from S. mobaraense (SmTG) is deposited in the Gene bank with accession No. AF531437.1. The nucleotide sequence encoding SmTG was codon optimized for production in $S$. cerevisiae (SmTG; DDBJ accession No. LC583746) by Eurofins genomics (Tokyo, Japan). The synthesized DNA encoding $S m$ TG was digested with SalI/BglII and inserted into the SalI/BglII sites of pGK425 (Ishii et al. 2009) to give the expression vector pGK425-TG. The S. cerevisiae BY4741 strain and GCI strain were transformed with pGK425TG using a lithium acetate method (Ito et al. 1983; Gietz et al. 1992) to yield the BY4741-TG and GCI-TG strains, respectively.

\section{Preparation of S. mobaraense transglutaminase}

Yeast transformants were pre-cultured in $5 \mathrm{~mL}$ of YPD at $30{ }^{\circ} \mathrm{C}$ and $200 \mathrm{rpm}$ overnight. This pre-culture was inoculated into $20 \mathrm{~mL}$ of SD medium in the presence of appropriate concentrations of amino acids and nucleobases for the BY4741-TG strain and additionally $0.5 \mu \mathrm{g} /$ $\mathrm{mL}$ aureobasidin A for the GCI-TG strain. The inoculation volumes were adjusted to an initial $\mathrm{OD}_{600}$ of 0.15 in $200 \mathrm{~mL}$ baffled Erlenmeyer flasks and cultured at $200 \mathrm{rpm}$ in a shaking incubator (BR-43FL, TAITEC, Saitama, Japan) at $30^{\circ} \mathrm{C}$.

For preparation of the $Y \times S m$ TG $(S m$ TG extracted from $S$. cerevisiae expressing $S m$ TG) solution, the supernatant from $Y \mathrm{~mL}$ of a $24 \mathrm{~h}$ cell culture was discarded after centrifugation at $3000 \times g$ for $5 \mathrm{~min}$ at $4{ }^{\circ} \mathrm{C}$. The collected cells were suspended in $300 \mu \mathrm{L}$ ice-cold TE buffer (100 mM Tris- $\mathrm{HCl}$ (pH 8.0), 2 mM 
ethylenediaminetetraacetic acid) and disrupted by a cell disruptor (Shake Master NEO, Bio Medical Sciences, Tokyo, Japan) with zirconia beads at $1500 \mathrm{rpm}$ for $10 \mathrm{~min}$. The cell debris were removed by centrifugation at $16,000 \times g$ for $10 \mathrm{~min}$ at $4{ }^{\circ} \mathrm{C}$. The supernatants ( $\mathrm{Sm}$ TG solution) were stored at $-80^{\circ} \mathrm{C}$ until use.

\section{Cross-linking assay of SmTG}

For the BSA cross-linking assay of $\operatorname{SmTG}$ at different reaction times, $40 \mu \mathrm{L}$ of the reaction buffer $\mathrm{BD}$ [1.25 mg/mL BSA, $50 \mu \mathrm{M}$ dithiothreitol (DTT)] and $10 \mu \mathrm{L}$ of the $1 \times \operatorname{Sm}$ TG solution in $100 \mathrm{mM}$ Tris $-\mathrm{HCl}$ $(\mathrm{pH} 8.0)$ were mixed and incubated for $0,30,60$ and $120 \mathrm{~min}$ at $50{ }^{\circ} \mathrm{C}$. For the BSA cross-linking assay with different volumes of $S m$ TG solutions, $40 \mu \mathrm{L}$ of the reaction buffer BD and $10 \mu \mathrm{L}$ of $1 \times, 5 \times$, or $10 \times S m \mathrm{TG}$ solution in $100 \mathrm{mM}$ Tris- $\mathrm{HCl}(\mathrm{pH} 8.0)$ were mixed and incubated for $120 \mathrm{~min}$ at $50^{\circ} \mathrm{C}$.

Because BSA required DTT as a reducing agent for cross-lining, the caseinate was used for cross-linking assay to evaluate the presence of several concentrations of glutathione as the other reducing agent for unknown inhibitor(s) (Bönisch et al. 2007). One hundred and sixty microliters of the reaction buffer containing $0.625 \mathrm{mg} / \mathrm{mL}$ sodium caseinate with $0-3.2 \mathrm{mM}$ glutathione and $40 \mu \mathrm{L}$ of the $1 \times \operatorname{Sm} \mathrm{TG}$ solution prepared from the BY4741-TG strain were mixed and incubated overnight at $50{ }^{\circ} \mathrm{C}$. Forty microliters of the reaction mixture was used for sodium dodecyl sulfate-polyacrylamide gel electrophoresis (SDS-PAGE) analysis. Sixty microliters of the reaction mixture was ultrafiltered by using Amicon ultrafiltration units (Merck KGaA, Darmstadt, Germany) to remove proteins whose molecular weights were under $100 \mathrm{kDa}$, and the concentrations of the cross-linked higher molecular weight proteins $(>100 \mathrm{kDa})$ were measured by staining with Coomassie Brilliant Blue (CBB) solution (NacalaiTesque, Kyoto, Japan).

Cross-linking activity of SmTG extracted from BY4741-TG and GCI-TG strains was measured by using caseinate as the substrate. Forty microliters of $0.625 \mathrm{mg} / \mathrm{mL}$ caseinate and $10 \mu \mathrm{L}$ of $12 \times \operatorname{SmTG}$ solution in $100 \mathrm{mM}$ Tris- $\mathrm{HCl}(\mathrm{pH} \mathrm{8.0)}$ were mixed and incubated overnight at $50{ }^{\circ} \mathrm{C}$. After the cross-linking reaction, $10 \mu \mathrm{L}$ of the reaction mixture was suspended into an equal volume of sample buffer for SDS-PAGE (Nacalai-Tesque) analysis, incubated for $3 \mathrm{~min}$ at $100{ }^{\circ} \mathrm{C}$, loaded onto a $12 \%$ SDS-PAGE gel, and the gel was stained by CBB stain One Super (Nacalai-Tesque). Relative level of protein was calculated from the intensity of each protein band using Image J software (https ://imagej.nih.gov/ij/).

\section{Measurement of SmTG activity}

Activity of $S m$ TGs was measured by incorporation of the fluorescent amine, dansyl cadaverine [ $N$-(5-aminopentyl)-5-dimethylamino-1-naphthalenesulfonamide, MDC] (Sigma-Aldrich, Missouri, USA), into $\mathrm{N}, \mathrm{N}$-dimethyl casein according to the fluorescence method reported (Liu et al. 2014). Twenty microliters of a $12 \times \operatorname{Sm}$ TG solution extracted from either the BY4741TG or GCI-TG strain was mixed with $460 \mu \mathrm{L}$ of the mixture (50 mM Tris- $\mathrm{HCl}(\mathrm{pH} 8.0), 0.2 \% \mathrm{~N}, \mathrm{~N}$-dimethyl casein, $13 \mu \mathrm{M} \mathrm{MDC}$ ). The assay mixture was incubated for $30 \mathrm{~min}$ at $37^{\circ} \mathrm{C}$ and the reaction terminated by adding $\left(\mathrm{NH}_{4}\right)_{2} \mathrm{SO}_{4}$ to a final concentration of $42 \mathrm{mM}$. The fluorescence intensity was measured by a microplate microplate reader Synergy HTX (BioTek, Vermont, USA) using excitation and emission wavelengths of 350 and $500 \mathrm{~nm}$, respectively.

\section{Analytical methods}

The cell concentration was determined by measuring the $\mathrm{OD}_{600}$ using a Gene Quant1300 spectrometer (GE Healthcare Life Sciences, Buckinghamshire, UK). The glutathione concentration was measured via a 5,5'-dithiobis (2-nitorobenzonic acid)-glutathione reductase recycling assay, as described previously (Hara et al. 2009).

\section{Results}

\section{Heterologous expression of SmTG in S. cerevisiae}

The gene encoding SmTG was codon optimized for expression in $S$. cerevisiae and transformed into the S. cerevisiae BY4741 strain. Cell growth of BY4741 expressing SmTG (BY4741-TG strain) was similar to that of the control strain. A solution of SmTG was obtained by disrupting the BY4741-TG strain expressing SmTG after cultivation for $24 \mathrm{~h}$. Intracellular

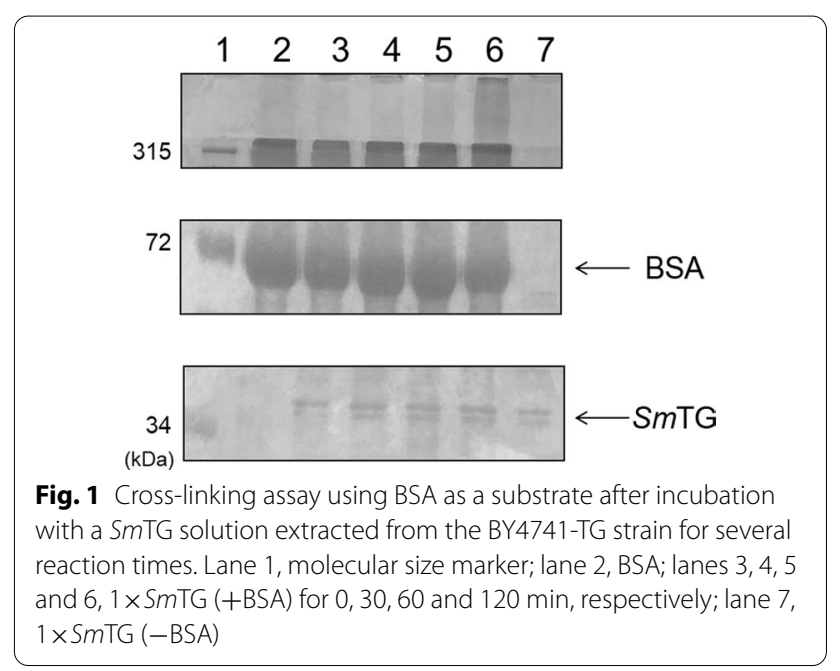


expression of SmTG was confirmed by SDS-PAGE analysis by the presence of a band of $\sim 37 \mathrm{kDa}$ (Fig. 1). Cross-linking activity of the SmTG solution extracted from the BY4741-TG strain was also confirmed using BSA as a substrate. A smeared band was observed when incubating BSA with SmTG, which represented polymerized BSA and the intensity of this smeared band was proportional to the reaction time (Fig. 1). Moreover, more BSA polymerized as the concentration of Sm TG was increased (Additional file 1: Fig. S1).

\section{Effect of glutathione addition on cross-linking activity of SmTG}

Glutathione was added to the SmTG solution extracted from the BY4741-TG strain to investigate the affect of glutathione on cross-linking activation of $\mathrm{Sm}$ TG (Fig. 2 and Additional file 1: Fig. S2). In general, milk proteins are good substrates for SmTG. In particular, caseins, major milk proteins, are a favorable substrate for SmTG to cross-link because they are non-globular and have limited tertiary structure, which makes them readily accessible to enzymes. Among them, both $\alpha$-casein and $\mathrm{K}$-casein have two cysteines and have been reported to play an important role in the formation of cross-links (Fox et al. 1998). Proteins that have molecular weights less than $100 \mathrm{kDa}$ were removed by ultrafiltration, and the remaining proteins were quantified to determine the level of caseinate cross-linking by SmTG. As shown in Fig. 2, proteins with molecular weights above $100 \mathrm{kDa}$ increased as the glutathione concentration increased from 0.2 to $0.8 \mathrm{mM}$ (Fig. 2). The concentration of proteins with molecular weights greater than $100 \mathrm{kDa}$ in the presence of $0.8 \mathrm{mM}$ glutathione was 1.5 -fold higher when compared with the results obtained in the absence

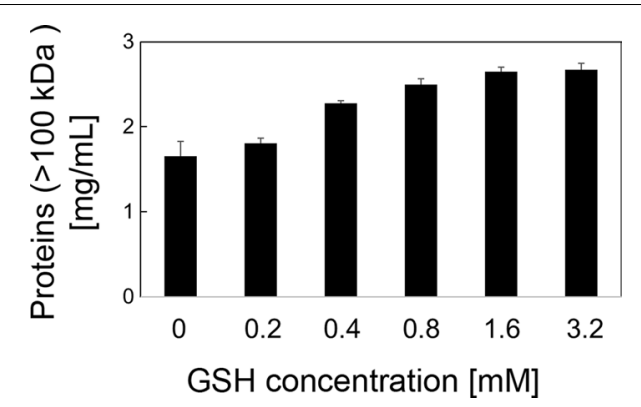

Fig. 2 Effect of reduced glutathione (GSH) addition on polymerization of caseinate by SmTG. The concentration of proteins whose molecular weights were more than $100 \mathrm{kDa}$ were detected after polymerization of caseinate by $0.2 \times 5 \mathrm{mTG}$ extracted from the BY4741-TG strain in the presence of different GSH concentrations of glutathione. Polymerization was saturated at concentrations above $0.8 \mathrm{mM}$ glutathione (Fig. 2).

\section{Heterologous overexpression of SmTG in a S. cerevisiae strain producing high amounts of glutathione}

We previously constructed the S. cerevisiae GCI strain, which produces higher levels of intracellular glutathione when compared with the parental S. cerevisiae strain (Hara et al. 2012). From the viewpoint of enhancing SmTG activity, S. cerevisiae host strain producing enhanced levels of glutathione for expression of $S m$ TG is an attractive approach to enhance SmTG activity. Therefore, in this study, the gene encoding SmTG was overexpressed in the GCI strain. Cell growth and glutathione production were compared between the GCI and BY4741 strains when overexpression of SmTG was induced (Additional file 1: Fig. S3). The cell growth of both strains was similar (Additional file 1: Fig. S3a). In contrast, glutathione content increased drastically in the GCI-TG strain when compared with that of the BY4741-TG strain (Additional file 1: Fig. S3b). The BY4741-TG strain and GCI-TG strain produced $0.0017 \mathrm{mM}$ and $0.16 \mathrm{mM}$ glutathione, respectively, after cultivation for $24 \mathrm{~h}$, although the expression levels of SmTG were the same between the both strains (Additional file 1: Fig. S3c). As shown in Fig. 2, addition of 1.6-3.2 mM glutathione showed saturated activity enhancement. Therefore, the $12 \times \operatorname{Sm} \mathrm{TG}$ solution extracted from the GCI-TG strain contatined saturated $1.92 \mathrm{mM}$ glutathione. The $12 \times \operatorname{SmTG}$ solution extracted from the BY4741-TG strain containing less than $0.2 \mathrm{mM}$ was used as an almost non-enhancement control (Fig. 2). The enhancement of SmTG activity extracted from the BY4741-TG strain and GCI-TG strain were compared (Fig. 3). The enhanced activity of SmTG extracted from the GCI-TG strain was 1.4-fold higher when compared with that of the BY4741-TG strain.

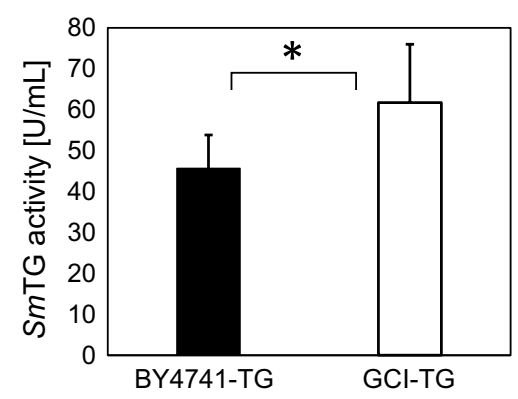

Fig. $3 \mathrm{SmTG}$ activity measured by the incorporation of MDC into $\mathrm{N}, \mathrm{N}$-dimethylcasein. $12 \times \mathrm{SmTG}$ extracted from BY4741-TG and GCI-TG strains were used for cross-linking reactions. The values are means and the error bars show the SD $(n=5)$. Statistically significant differences are indicated by an asterisk $(p=0.023)$ 

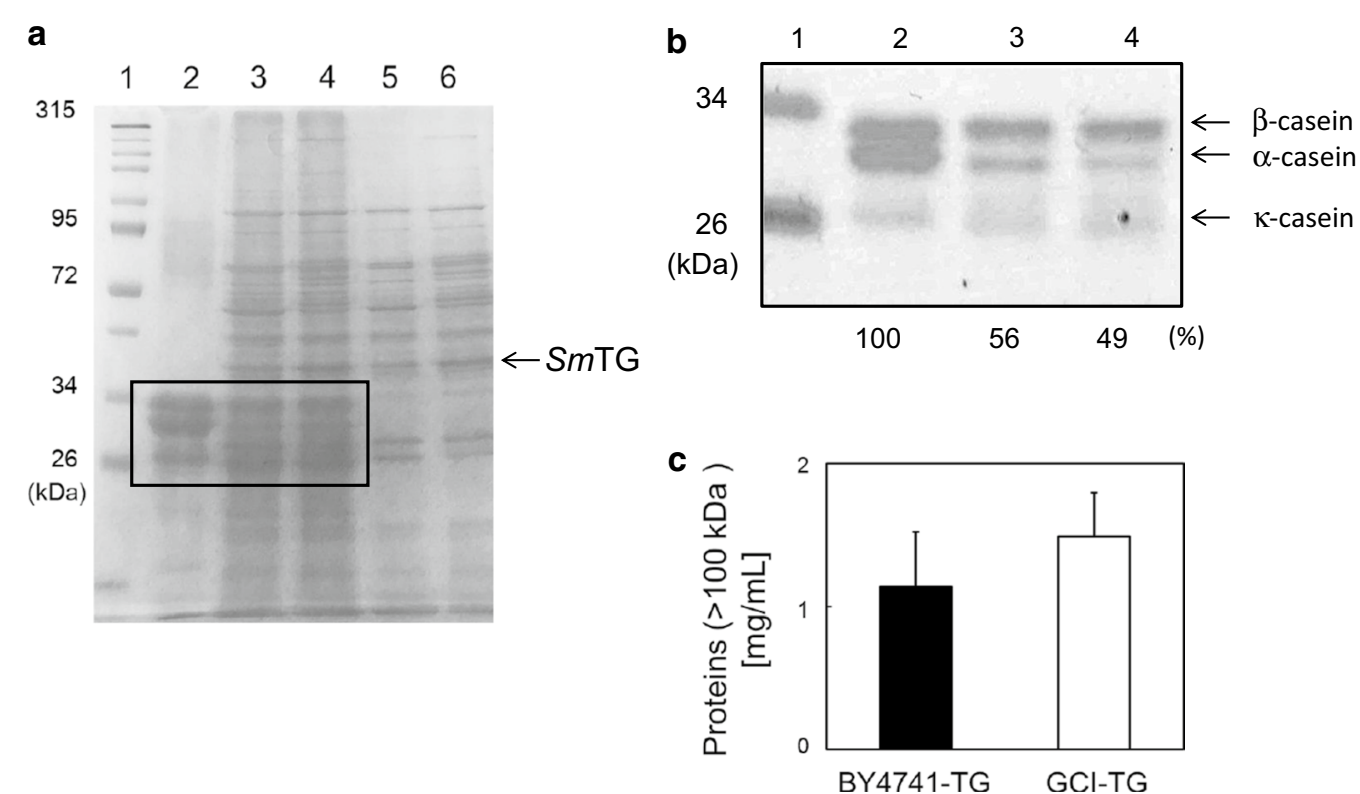

Fig. 4 Polymerization of caseinate by SmTG extracted from BY4741-TG and GCl-TG strains. Each sample volume loaded was $20 \mu \mathrm{L}(\mathbf{a})$ and $5 \mu \mathrm{L}$ (b). a Lane 1, protein molecular size marker; lane 2, caseinate control; lane 3, polymerized caseins by $12 \times$ SmTG extracted from the BY4741-TG strain; lane 4, polymerized caseins by $12 \times$ SmTG extracted from the GCI-TG strain; lane 5, BY4741-TG extract; lane 6, GCI-TG extract. $\mathbf{b}$ Expanded region of the SDS-PAGE in (a boxed region). Ratios of cross-linked a-casein were calculated from the intensity of each a-casein band and represented as relative values (\%). c The concentration of proteins whose molecular weights were more than $100 \mathrm{kDa}$, were detected after polymerization of caseinate by $12 \times$ SmTG extracted from the BY4741-TG and GCI-TG strain

This result indicates that activity of $\operatorname{SmTG}$ expressed in the GCI strain was enhanced because of the higher glutathione content present when compared with that of the BY4741 strain.

Finally, the cross-linking activity of SmTG extracted from that GCI-TG strain was evaluated using caseinate as a substrate. As shown in Fig. 4a, the intensities of higher molecular-weight bands increased when using the SmTG solution extracted from the GCI-TG strain rather than that from the BY4741-TG strain. The yields of polymerized $\alpha$-caseins were estimated to be $44 \%$ and $51 \%$, because the residual $\alpha$-caseins were calculated to be $56 \%$ and $49 \%$ from the BY4741-TG strain and GCITG strain, respectively. These results indicate that $S m$ TG extracted from the GCI-TG strain showed enhanced cross-linking activity of $\alpha$-casein because of the higher content of glutathione present in the GCI-TG strain when compared with that of the BY4741-TG strain. Proteins that have molecular weights less than $100 \mathrm{kDa}$ were removed by ultrafiltration, and the remaining proteins were quantified to determine the level of caseinate crosslinking by SmTG extracted from the BY4741-TG strain and the GCI-TG strain. As shown in Fig. 4c, the concentration of proteins with molecular weights greater than $100 \mathrm{kDa}$ obtained from the GCI-TG strain was 1.3-fold higher when compared with the result obtained from the BY4741-TG strain.

\section{Discussion}

TG is used frequently as an industrial enzyme, especially in the food industry, and reports describing its use in the food industry are numerous (Miwa 2020). The biggest advantage of TG from S. mobaraense ( $\mathrm{Sm}$ TG) is its suitability in a variety of applications. In this study, SmTG expressed in S. cerevisiae was confirmed to have polymerizing activity. Furthermore, SmTG extracted from the higher glutathione producing $S$. cerevisiae, which overexpresses $G S H 1$ and $G S H 2$ together with SmTG, also showed activity. The cell growth of both BY4741-TG and GCI-TG strains decreased after $24 \mathrm{~h}$ cultivation (Additional file 1: Fig. S3a). This decrease in cell growth is hypothesized to be cell damage caused by polymerization of various intracellular proteins required for survival. However, the reduction in growth rate was small and may not pose as an issue when producing SmTG in S. cerevisiae. Polymerization activity of $S m$ TG increased in the presence of glutathione concentrations up to $1.6 \mathrm{mM}$ when caseinate was used as the 
substrate (Fig. 2). The cross-linking assay was carried out using $12 \times S m$ TG extracted from the GCI-TG strain, which contained $1.92 \mathrm{mM}$ glutathione after cultivation for $24 \mathrm{~h}$. The crosslinking activity using $12 \times \operatorname{Sm} \mathrm{TG}$ extracted from the GCI-TG strain was enhanced by 1.4-fold when compared with the $12 \times \operatorname{Sm} \mathrm{TG}$ extracted from the BY4741-TG strain (Fig. 3). This fold increase is similar to the value (1.5-fold) observed when glutathione was added externally at concentrations above $0.8 \mathrm{mM}$ (Fig. 2). Thus, the production of active SmTG because of the higher levels glutathione produced in the engineered $S$. cerevisiae is advantageous for crosslinking activity by $S m$ TG.

Miwa (2020) reported that crosslinking of pasteurized milk was enhanced in the presence of $0.02-$ $0.2 \mathrm{mM}$ glutathione (Miwa 2020). Mixtures of SmTG and glutathione were supplied from food companies (Bönisch et al. 2007). In the current study, we showed the potential of obtaining a mixture of SmTG and glutathione produced simultaneously by overexpression of $S m$ TG in an engineered S. cerevisiae strain producing high levels of glutathione.

Glutathione is industrially produced by fermentation of $S$. cerevisiae. In this study, we succeeded in integrating the production of SmTG and glutathione using $S$. cerevisiae as a host strain. This simple strategy for production of active SmTG in S. cerevisiae should reduce production costs and waste as both TG and GSH will be available from one source.

\section{Supplementary Information}

The online version contains supplementary material available at https://doi. org/10.1186/s13568-020-01176-3.

\footnotetext{
Additional file 1: Figure S1. Cross-linking assay using BSA as a substrate after incubation for 120 min with several volumes of SmTG solution extracted from the BY4741-TG strain. Lane 1, molecular size marker; lane 2, BSA only; lanes 3, 4 and $5,1 \times, 5 \times$ and $10 \times \operatorname{SmTG}(+B S A)$, respectively; lanes 6,7 and $8,1 \times, 5 \times$ and $10 \times \operatorname{SmTG}(-B S A)$, respectively. Figure S2. Effect of adding reduced glutathione to polymerization of caseinate by SmTG. SDS-PAGE profiles show the protein pattern of caseinate after incubation with SmTG. $1 \times$ SmTG extracted from the BY4741-TG strain was used. Lane 1, molecular size marker; lane 2, caseinate only; lanes 3, 4, 5, 6, 7 and 8, caseinate, SmTG and 0, 0.2, 0.4, 0.8, 1.6 and 3.2 mM glutathione, respectively; lane 9 , SmTG only. The polymerized caseins (molecular weight $>100 \mathrm{kDa}$ ) presented in the top panel were recovered and measured as shown in Fig. 2. Figure S3. Growth and glutathione production of S. cerevisiae expressing SmTG. (a) Time course of cell growth. Solid and dotted lines represent the BY4741-TG and GCI-TG strains, respectively. (b) Glutathione concentrations in $1 \times$ SmTG solutions extracted from the BY4741-TG strain (black) and GCl-TG strain (white). (c) Expression level of SmTG after cultivation for $24 \mathrm{~h}$. lane 1, BY4741-TG strain; lane 2, GCI-TG strain. Expression level of SmTG was calculated from the intensity of each SmTG band and represented as relative values (\%). The values are means and the error bars show the SD $(n=3)$.
}

\section{Acknowledgements}

The authors are grateful to Dr. J. Ishii (Kobe University) for providing us with pGK425.

\section{Authors' contributions}

All authors designed the study and wrote the manuscript. YHH and YM conducted the experiments. $\mathrm{KYH}$ advised on the project and was involved in revising the manuscript. KYH coordinated this study, contributed to the major funding support and managed the project. All authors read and approved the final manuscript.

\section{Funding}

This study was supported by the Special Coordination Funds for Promoting Science and Technology, MEXT, Japan, Grant-in-Aid for Scientific Research (C) 16K00616, and the JST-Mirai Program Grant Number JPMJMI17EJ.

\section{Availability of data and materials}

All data and materials are available.

\section{Ethics approval and consent to participate}

This manuscript does not contain any studies with human participants or animals performed by any of the authors.

\section{Consent for publication}

All authors consent the publication.

\section{Competing interests}

The authors declare that they have no competing interests.

\section{Author details}

${ }^{1}$ Department of Environmental and Life Sciences, School of Food and Nutritional Sciences, University of Shizuoka, 52-1 Yada, Suruga-ku, Shizuoka 422-8526, Japan. ${ }^{2}$ Graduate Division of Nutritional and Environmental Sciences, University of Shizuoka, 52-1 Yada, Suruga-ku, Shizuoka 422-8526, Japan.

Received: 10 October 2020 Accepted: 30 December 2020

Published online: 07 January 2021

\section{References}

Abou-Soliman NHI, Sakr SS, Awad S (2017) Physico-chemical, microstructural and rheological properties of camel-milk yogurt as enhanced by microbial transglutaminase. J Food Sci Technol 54:1616-1627

Ando H, Adachi M, Umeda K, Matsuura A, Nonaka M, Uchio R, Tanaka H, Motoki M (1989) Purification and characteristics of a novel transglutaminase derived from microorganism. Agric Biol Chem 53:2613-2617

Bönisch MP, Lauber S, Kulozik U (2007) Improvement of enzymatic crosslinking of casein micelles with transglutaminase by glutathione addition. Int Dairy J 17:3-11

Folk JE (1980) Transglutataminases. Ann Rev Biochem 49:517-531

Fox PF, Uniacke-Lowe T, McSweeney PLH, O'Mahony JA (1998) Dairy chemistry and biochemistry. Blackie Academic \& Professional, Glasgow

Gerrard J, Fayle S, Wilson A, Newberry M, Ross M, Kavale S (1998) Dough properties and crumb strength of white pan bread as affected by microbial transglutaminase. J Food Sci 63:472-475

Gietz D, St Jean A, Woods RA, Schiestl RH (1992) Improved method for high efficiency transformation of intact yeast cells. Nucleic Acids Res 20:1425

Hara KY, Shimodate N, Hirokawa Y, Ito M, Baba T, Mori H, Mori H (2009) Glutathione production by efficient ATP-regenerating Escherichia coli mutants. FEMS Microbiol Lett 297:217-224

Hara KY, Kiriyama K, Inagaki A, Nakayama H, Kondo A (2012) Improvement of glutathione production by metabolic engineering the sulfate assimilation pathway of Saccharomyces cerevisiae. Appl Microbiol Biotechnol 94:1313-1319 
Hara KY, Aoki N, Kobayshi J, Kiriyama K, Nishida K, Araki M, Kondo A (2015) Improvement of oxidized glutathione fermentation by thiol redox metabolism engineering in Saccharomyces cerevisiae. Appl Microbiol Biotechnol 99:9771-9778

Ikura K, Yoshikawa M, Sasaki R, Chiba H (1981) Incorporation of amino acids into food proteins by transglutaminase. Agric Biol Chem 45:2587-2592

Ishii J, Izawa K, Matsumura S, Wakamura K, Tanino T, Tanaka T, Ogino C, Fukuda $\mathrm{H}$, Kondo A (2009) A simple and immediate method for simultaneously evaluating expression level and plasmid maintenance in yeast. J Biochem 145:701-708

Itaya H, Kikuchi Y (2008) Secretion of Streptomyces mobaraensis pro-transglutaminase by coryneform bacteria. Appl Microbiol Biotechnol 78:621-625

Ito H, Fukuda Y, Murata K, Kimura A (1983) Transformation of intact yeast cells treated with alkali cations. J Bacteriol 153:163-168

Kanaji T, Ozaki H, Takao T, Kawajiri H, Ide H, Motoki M, Shimonishi Y (1993) Primary structure of microbial transglutaminase from Streptoverticillium sp. strain s-8112. J Biol Chem 268:11565-11572

Kashiwagi T, Yokoyama KI, Ishikawa K, Ono K, Ejima D, Matsui H, Suzuki E (2002) Crystal structure of microbial transglutaminase from Streptoverticillium mobaraense. J Biol Chem 277:44252-44260

Kuraishi C, Sakamoto J, Yamazaki K, Susa Y, Kuhara C, Soeda T (1997) Production of restructured meat using microbial transglutaminase without salt or cooking. J Food Sci 62:488-490

Kurth L, Rogers P (1984) Transglutaminase catalyzed cross-linking of myosin to soya protein, casein and gluten. J Food Sci 49:573-576

Li Y, Wei G, Chen J (2004) Glutathione: a review on biotechnological production. Appl Microbiol Biotechnol 66:233-242
Liu Y, Lin S, Zhang X, Liu X, Wang J, Lu F (2014) A novel approach for improving the yield of Bacillus subtilis transglutaminase in heterologous strains. J Ind Microbiol Biotechnol 41:1227-1235

Lorand L, Conrad SM (1984) Transglutaminases. Mol Cell Biochem 58:9-35 Miwa N (2020) Innovation in the food industry using microbial transglutaminase: keys to success and future prospects. Anal Biochem 597:113638-113646

Nonaka M, Tanaka H, Okiyama A, Motoki M, Ando H, Umeda K, Matsuura A (1989) Polymerization of several proteins by Ca2-independent transglutaminase derived from microorganisms. Agric Biol Chem 53:2619-2623

Özçelik AT, Ersöz F, İnan M (2019) Extracellular production of the recombinant bacterial transglutaminase in Pichia pastoris. Protein Expr Purif 159:83-90

Salis B, Spinetti S, Scaramuzza S, Bossi M, Jotti GS, Tonon G, Crobu D, Schrepfer R (2015) High-level expression of a recombinant active microbial transglutaminase in Escherichia coli. BMC Biotechnol 15:84

Savoca MP, Tonoli E, Atobatele AG, Verderio EAM (2018) Biocatalysis by transglutaminases: a review of biotechnological applications. Micromachines 9:562-585

Schmacht M, Lorenz E, Senz M (2017) Review microbial production of glutathione. World J Microbiol Biotechnol 33:106-119

\section{Publisher's Note}

Springer Nature remains neutral with regard to jurisdictional claims in published maps and institutional affiliations.

\section{Submit your manuscript to a SpringerOpen ${ }^{\circ}$ journal and benefit from:}

- Convenient online submission

- Rigorous peer review

- Open access: articles freely available online

- High visibility within the field

- Retaining the copyright to your article

Submit your next manuscript at $\boldsymbol{\nabla}$ springeropen.com 